\title{
The role of interchange fees in ATM networks
}

\author{
Jocelyn Donze*and Isabelle Dubec ${ }^{\dagger}$
}

July 28,2005

\begin{abstract}
We develop a model to study the deployment of shared ATMs when an interchange system compensates banks for processing non-customers' withdrawals. The interchange fee is chosen cooperatively by banks. We show that a high interchange fee softens competition on the market for deposits but increases competition to process withdrawals. As the former effect dominates the latter, profits are increasing with the interchange fee up to some level. This confirms the presumption that the interchange system can be used as a collusive device by banks. We show that the cooperatively chosen interchange fee does not decrease when the number of banks gets higher or when deployment costs decrease. These results are consistent with the empirical evidence concerning interchange fees. The model also predicts that the size of the shared ATM network exceeds the socially optimal level when the number of banks is large enough.
\end{abstract}

JEL No. L1, G2

\footnotetext{
*GREMAQ, (UMR 5603 CNRS) Toulouse; jdonze@univ-tlse1.fr

†GREMAQ (UMR 5603 CNRS) Toulouse; dubec@univ-tlse1.fr.
} 


\section{Introduction}

In many countries, banks share their automated teller machines (ATMs) in regional or national networks: a cardholder of a bank can use an ATM of another bank of the network and make a "foreign withdrawal". The cardholder's bank pays an interchange fee to the ATM-owning bank to compensate it for the costs of deploying the ATM and providing the service. In general, this fee is set collectively by the network members. A network switch, typically owned by banks, acts as a central device and permits clearing.

Several observations have been made about interchange fees. ${ }^{1}$ First, evidence suggests that they involve a substantial mark-up over the average cost of providing ATM services. In Australia, Great Britain and the USA, the mark-up is close to 100\%. Second, interchange fees have remained largely unchanged over the last two decades despite the fall of deployment and communication costs and the entry of new banks into the ATM market.

Economists and antitrust authorities consider the joint determination of prices with suspicion. They argue that the cooperative setting of interchange fees explains why they remain sticky above the average cost of providing ATM services (See Balto (2000)). On the other hand, other economists suggest that interchange fees are necessary to guarantee the universal access to ATMs and are mainly a transfer payment to equilibrate the costs and benefits between the cardholders' banks and the ATM owners (See Cruickshank report (2000)).

This paper studies the role of interchange fees in ATM networks and addresses the following questions: Why are interchange fees so much higher than the average cost of ATM services? What is the effect of the cooperative choice of interchange fees on banking pricing? Is there over- or under-provision of ATMs compared to the social optimum?

To answer these questions we set up a model in which banks set the interchange fee cooperatively but choose the ATM deployment and the prices non-cooperatively. Consumers

\footnotetext{
${ }^{1}$ See Reserve Bank of Australia (2000), Cruickshank report (2000) and McAndrews (2003)
} 
pay a unique account fee to their bank to obtain both basic banking services and the unlimited access to the shared ATM network. Banks compete à la Bertrand on the deposit market. We show that banks collude on high interchange fees in order to reduce competition for deposits. The consequence is that the size of the shared network is above the socially optimal level if there are sufficiently many banks. The properties of the interchange fee jointly set by banks fit the empirical evidence: the fee exceeds the marginal cost of processing a withdrawal and it does not decrease when the number of banks grows or when deployment costs fall.

Let us get an intuition for the results. As there is no ATM usage fees, the shared network is a public good for cardholders. Banks do not deploy ATMs to attract deposits, but rather to process withdrawals and receive interchange fees. When the interchange fee exceeds the marginal cost of processing a withdrawal, each bank is willing to process the withdrawals of competitors' cardholders and to reduce its own depositors' foreign withdrawals. Hence, there must be a positive mark-up of the interchange fee over the processing marginal cost to give banks incentives to deploy ATMs.

Nevertheless, the interchange fee is not only a transfer payment, but also a collusive device. To understand why, observe that there are two effects when banks raise the interchange fee. On the one hand, the competition for processing withdrawals is strengthened, more ATMs are opened and banks' deployment costs increase. On the other hand, each bank is less willing to accept depositors because the foreign withdrawals they make induce high interchange outflows. Consequently the competition for deposits is relaxed, account fees increase and banks' revenues rise with the interchange fee. We show that as long as the account fee is below depositors' reservation price, the effect on revenues dominates the effect on costs so that banks' profits are increasing with the interchange fee. Nevertheless they are not indefinitely increasing. Depositors' reservation price gets higher with the size of the ATM network, but less and less as the network is expanding. When the interchange fee becomes very high, the account fee is bounded from above by the reservation price and does 
not rise enough to cover the additional costs of ATM deployment: profits begin to decrease with the interchange fee.

At the cooperative stage, banks choose the interchange fee to maximize joint profits. We show that the network size is over-optimal if there are many banks or consumers' reservation prices are high. When the first condition is met, the over-provision of ATMs comes from the fierce competition between banks to process withdrawals and receive interchange fees. When the second condition is met, banks choose a high interchange fee to extract consumers' surplus through high account fees and many ATMs are deployed. When the two previous conditions are not satisfied, the ATM deployment may be optimal.

In our model, customers pay a fixed account fee to their bank, but there is no ATM usage fee. This pricing scheme is observed in many European countries. ${ }^{2}$ In other countries like the USA, banks impose surcharges on non-customers for using their ATMs and foreign fees on their depositors for making foreign withdrawals. Massoud and Bernardt (2000a, 2002b) and Croft and Spencer (2004) consider models more suited to the American ATM market. The American pricing scheme leads to different behaviors of banks and customers. First, the shared network is no longer a public good for cardholders: when several ATMs are located at the same distance from a cardholder, the cardholder prefers her bank's machine. Second, surcharging affects the choice of where to establish deposits: consumers prefer banks with large ATM networks to avoid being surcharged. Third, surcharges enhance the ATM deployment: banks deploy ATMs even if the interchange fee is nil because they receive surcharges from non-depositors.

Massoud and Bernardt (2002a, 2002b) consider a framework without interchange fees in which banks impose surcharges on non-depositors. In (2002b), they show that surcharging

\footnotetext{
${ }^{2}$ It is for example the case in France, Great Bitain, Italy and the Netherlands. In these countries, the ATM usage is only exceptionally charged by banks. See Bolt (2003) for the Netherlands, Ganguly and Milne (2001) and the LINK network (2004) for the UK and the GIE CB (2004) for France.
} 
leads to an over-provision of ATMs. Banks propose a two-part tariff to their customers and a linear surcharge to non-customers. Consequently banks can extract their own customers' surplus more efficiently and they compete for a larger customer base. As customers prefer to choose a bank owning many ATMs, banks over-provide ATMs and raise their surcharges to make competitors' banking services less attractive. In an empirical work, Massoud et al. (2004) show that large banks with many ATMs increase their deposit market shares at the expense of smaller banks that have fewer ATMs: surcharges consolidate the market power of large banks. In our model, all ATMs are created equal from the perspective of consumers and banks cannot attract depositors with their own ATMs. In this case, the over-provision of ATMs is a consequence of the fierce competition to process withdrawals and receive interchange fees.

Croft and Spencer (2004) consider a framework with interchange fees, foreign fees and surcharges. They analyze the issue of surcharging or not when two banks have exogenous equal fleets of ATMs. The authors show that foreign fees serve to maximize joint profits while the interchange fee is set at the marginal cost of an ATM transaction and surcharges are banned. In our model, such a result cannot occur: if the interchange fee is equal to the processing marginal cost, banks do not deploy any ATM.

Our model is related to the one developed by Matutes and Padilla (1993). They study the incentives of competing banks to share their ATM networks. They show that introducing interchange fees makes sharing more attractive. We start from this result by assuming a single shared network. We extend their model by endogenizing the choice of the interchange fee and the ATM deployment.

The paper is organized as follows. In section 2 , we set up the model. In section 3 , we solve the equilibrium in deployment and price for a given interchange fee. Section 4 deals with the cooperative choice of the interchange fee by banks and its welfare properties. Section 5 concludes. 


\section{The model}

Banks and consumers of banking services are involved in the game. The measure of consumers is normalized to one.

Banks. There are $b \geq 2$ banks that provide homogeneous basic banking services (deposit management, cash withdrawals at the bank's branch office, etc.). Banks deploy compatible ATMs in a uniform urban setting where consumers shop and withdraw cash. The number of ATMs deployed by bank $i$ is $n_{i} \in \Re^{+}$. The total size of the network is $n=\sum_{i=1}^{b} n_{i}$. As the measure of consumers is one, $n$ and the $n_{i}$ s are numbers of ATMs per consumer. The fixed cost of deploying an ATM is denoted by $c$.

Each bank $i$ charges a fixed account fee $p_{i}$ for the basic services and a debit card allowing customers to withdraw cash at any ATM of the shared network. There is no ATM usage fee.

The marginal cost of the basic services is denoted $c_{b}$. The marginal cost of processing a withdrawal is independent of the cardholder's affiliation and is normalized to zero. When a cardholder of bank $i$ makes a withdrawal at an ATM of bank $j$, bank $i$ pays an interchange fee, $a$, to bank $j$.

Consumers. They choose the bank they want to become a cardholder of. The net surplus of a consumer is

$$
\left\{\begin{array}{l}
v_{b}+v(n)-p_{i} \text { if the consumer chooses bank } i \\
0 \text { if the consumer does not join a bank. }
\end{array}\right.
$$

$v_{b}$ is the surplus from getting basic banking services. $v(n)$ is the surplus from accessing to $n$ ATMs. Since there is no usage fee, cardholders withdraw cash without considering which banks the ATMs belong to, and their surplus depends on the total size of the ATM network. We assume that $v($.$) is increasing and strictly concave: increasing the size of$ the network benefits customers because obtaining cash is easier, nevertheless the marginal benefit decreases with the network size. We also make the assumption that $v(0)=0$, 
$\lim _{n \rightarrow 0} v^{\prime}(n)>c, \lim _{n \rightarrow \infty} v^{\prime}(n)=0$ and $v_{b} \geq c_{b}$.

We assume that each cardholder makes one withdrawal. We have the following framework in mind. Cardholders are uniformly located in the urban setting when they experience a need of cash. Since there is no usage fee, cardholders withdraw cash at the nearest ATM. Each bank's ATMs are uniformly located to maximize the number of withdrawals processed and the interchange revenues. Consequently, the way cardholders allocate their withdrawals only depends on the ATM market shares: $n_{i} / n$ is the total number of withdrawals made at bank i’s ATMs.

Competition and profits. We assume that banks compete $\grave{a}$ la Bertrand on the deposit market: if bank $i$ charges a price below those of all other banks and consumers' surplus is non-negative, then $i$ gets the entire market. If several banks propose the lowest price and consumers' surplus is non-negative, we assume that banks share the market equally. Formally, let $p_{\min }=\min \left\{p_{1}, \ldots p_{b}\right\}$ and let $b_{\min }$ denote the number of banks that charge $p_{\min }$ : $b_{\min }=\operatorname{card}\left\{i \mid p_{i}=p_{\min }\right\}$. Bank $i$ 's market share of deposits is

$$
D_{i}=\left\{\begin{array}{l}
1 / b_{\min } \text { if } p_{i}=p_{\min } \text { and } p_{\min } \leq v_{b}+v(n) \\
0 \text { otherwise }
\end{array}\right.
$$

Note that $\sum_{j} D_{j}=1$ if $p_{\min } \leq v_{b}+v(n)$. We say that a bank is active (respectively inactive) if its deposit market share is positive (respectively zero). Note that an inactive bank can have ATMs and process withdrawals. We assume that a bank indifferent between being active and being inactive chooses to be active.

The profit of bank $i$ is

$$
\pi_{i}\left(n_{1}, \ldots n_{b}, p_{1}, \ldots p_{b}\right)=\left(p_{i}-c_{b}\right) D_{i}-a \frac{n-n_{i}}{n} D_{i}+a \frac{n_{i}}{n} \sum_{j \neq i} D_{j}-c n_{i} .
$$

The first term of the right-hand side of (1) is the net revenue from offering accounts. The second term corresponds to the interchange fees paid to the other banks when bank $i$ 's 
cardholders make foreign withdrawals. The third term represents the revenue coming from the interchange fees paid by the other banks when their cardholders use an ATM of bank $i$. The last term corresponds to the deployment costs.

Timing of the game. First, banks choose the interchange fee $a$ collectively in order to maximize the industry profits. Second, banks simultaneously and non-cooperatively choose the number of ATMs they deploy, $n_{i}, i=1, \ldots b$ and the account fees, $p_{i}, i=1, \ldots b$. Third, each consumer chooses her bank and makes one withdrawal.

Welfare Analysis. Before solving the equilibria of the game, we characterize the size of the network, $n^{o}$, that maximizes the total surplus, $v_{b}-c_{b}+v(n)-c n$, the sum of consumers' surplus and banks' profits. The optimal $n^{o}$ solves

$$
v^{\prime}\left(n^{o}\right)=c
$$

It is positive because $\lim _{n \rightarrow 0} v^{\prime}(n)>c$. At the social optimum, the marginal benefit of deploying an ATM equals the marginal cost of deployment.

\section{The equilibria}

We solve the game in deployment and price for a given interchange fee $a$. A Nash equilibrium of the game is a profile $\left\{n_{1}^{e}(a), \ldots, n_{b}^{e}(a), p_{1}^{e}(a), \ldots, p_{b}^{e}(a)\right\}$ such that for any $i \in\{1, \ldots b\}$ and any $\left(n_{i}^{d}, p_{i}^{d}\right), \pi_{i}\left(n_{i}^{e}(a), n_{-i}^{e}(a), p_{i}^{e}(a), p_{-i}^{e}(a)\right) \geq \pi_{i}\left(n_{i}^{d}, n_{-i}^{e}(a), p_{i}^{d}, p_{-i}^{e}(a)\right)$.

The game has two types of equilibria: equilibria with $b$ active banks and equilibria with a single active bank. For simplicity of exposition, we focus on equilibria with $b$ active banks. ${ }^{3}$ To provide an intuition of the way equilibria are obtained, we proceed in two steps: first, we define a necessary condition on prices for an equilibrium to exist. Second, we characterize the

\footnotetext{
${ }^{3}$ One can show that equilibria with one active bank are not relevant to the analysis as the corresponding industry profits are not maximized.
} 
equilibrium deployment given these prices. Formal proofs appear in appendix; we notably verify that there is no profitable deviation in both price and deployment.

Consider the problem of bank $i$ when fixing its account fee. The total marginal cost of a customer is composed of two parts: $c_{b}$ and $a$. The first term is the marginal cost of basic services. The second term can be interpreted as bank $i$ 's expected marginal interchange cost, which is itself the sum of two elements: (i) a direct expected cost, $\left(n-n_{i}\right) a / n$, that bank $i$ pays for the new customer's foreign withdrawals, (ii) an opportunity $\operatorname{cost} n_{i} a / n$ that corresponds to a loss of interchange revenues for bank $i$. Indeed, if this customer opened an account with bank $j \neq i$, the expected revenue from interchange fees would be $n_{i} a / n$. By making this customer opening an account with bank $i$, bank $i$ loses these expected fees, and we therefore count $n_{i} a / n$ as an opportunity cost. In appendix 1 , we verify that Bertrand competition leads to symmetric prices equal to the total marginal cost, $c_{b}+a$. Hence,

Lemma 1 If an equilibrium $\left\{n_{1}^{e}(a), \ldots, n_{b}^{e}(a), p_{1}^{e}(a), \ldots, p_{b}^{e}(a)\right\}$ with $b$ active banks exists, then equilibrium prices are

$$
p_{i}^{e}(a)=c_{b}+a \quad \text { for any } i \in\{1, \ldots b\}
$$

\section{Proof. Appendix 1}

The lemma states a key point of the analysis: the net accounting revenue from offering an account, $p_{i}^{e}(a)-c_{b}$, is positive and equal to $a$, the interchange fee chosen by banks at the cooperative stage. When $a$ raises, banks are less willing to accept depositors and prices raises.

Given the prices of lemma 1 , bank $i^{\prime}$ s profit is

$$
\pi_{i}=a \frac{n_{i}}{n}-c n_{i}
$$

Let us ignore consumers' participation constraint, $v(n)+v_{b} \geq c_{b}+a$, for the moment. Bank 
$i$ maximizes its profit with respect to $n_{i}$. The first order condition (FOC) is

$$
a \frac{n-n_{i}}{n^{2}}-c=0
$$

Summing over the $b$ FOCs gives the total network size:

$$
n^{*}(a)=\frac{b-1}{b} \times \frac{a}{c} .
$$

For this deployment to be an equilibrium, we must verify two extra conditions:

(i) Consumers' participation constraint must be satisfied :

$$
v\left(n^{*}(a)\right)+v_{b} \geq c_{b}+a .
$$

This condition is equivalent to $a \leq a^{*}$ where $a^{*}$ is defined by

$$
v\left(\frac{b-1}{b} \times \frac{a^{*}}{c}\right)+v_{b}=c_{b}+a^{*} .
$$

$a^{*}$ is illustrated in figure 1. It is the lowest interchange fee that permits to extract the entire consumers' surplus at equilibrium. One can verify that $a^{*}$ is increasing in the number of banks, $b$, increasing in $v_{b}-c_{b}$, and decreasing in the deployment cost $c$.

\section{[Insert figure 1]}

(ii) Banks must have no incentive to deviate in $n_{i}$ and $p_{i}$ at the same time. We verify this is the case in appendix 2 .

Hence we have identified a first family of equilibria when $a$ is below $a^{*}$. We sum up their characteristics before describing a second family of equilibria when $a$ is above $a^{*}$.

Proposition 1 Suppose that the banks cooperatively choose $a \leq a^{*}$ where $a^{*}$ is given in (6). There exists a unique equilibrium $\left\{n_{1}^{*}(a), \ldots n_{b}^{*}(a), p_{1}^{*}(a), \ldots p_{b}^{*}(a)\right\}$ with $b$ active banks characterized by

$$
n^{*}(a)=\frac{b-1}{b} \times \frac{a}{c}
$$


and for any $i \in\{1, \ldots b\}$,

$$
\left\{\begin{array}{l}
n_{i}^{*}(a)=\frac{n^{*}(a)}{b} \\
p_{i}^{*}(a)=c_{b}+a .
\end{array}\right.
$$

Proof. Appendix 2

The total ATM deployment coming from the first family of equilibria, $n^{*}(a)$, is illustrated in figure 1 (the shape line for $a \leq a^{*}$ ). Not surprisingly, the number of ATMs deployed by each bank is decreasing with the deployment $\operatorname{cost} c$. More interestingly, this number is increasing with the interchange fee on $\left[0, a^{*}\right]$. It is equal to zero if the interchange fee is equal to the marginal cost of processing a withdrawal, which is normalized to zero. In this case, each bank free-rides on its rivals' ATMs. If the interchange fee is positive, banks compete for processing withdrawals: they deploy ATMs to limit the number of foreign withdrawals made by their cardholders and to attract withdrawals made by their competitors' cardholders.

At equilibrium, the accounting outflows and inflows of interchange fees are perfectly balanced. Bank $i$ 's profit is equal to the revenue from offering accounts $\left(p_{i}^{*}(a)-c_{b}\right) / b=a / b$ minus the deployment cost $c n_{i}^{*}(a)=(b-1) a / b^{2}$ :

$$
\pi_{i}^{*}(a)=\frac{a}{b^{2}}, i=1, \ldots b .
$$

The profit is positive when $a>0$. If banks have no ATM network (which corresponds to the case $a=0$ ), their profit is nil: the severe price competition on the deposit market leads to the Bertrand paradox. A positive interchange fee allows banks to escape from this paradox through a "collective raising rivals' cost": while interchange flows disappear from profits at equilibrium, the mark-up of the price over the marginal cost of basic services, $p_{i}^{*}-c_{b}$, is positive and equal to $a$, the interchange fee collectively chosen by banks. The corresponding revenue outweighs the ATM deployment cost.

The profit is an increasing function of the interchange fee on $\left[0, a^{*}\right]$. Raising the interchange fee has two effects on banks' profit. There is a negative effect due to a more severe 
competition to attract withdrawals. More ATMs are deployed and banks' costs increase. But, there is also a positive effect: higher interchange fees allow higher prices and hence a more collusive behavior of banks on the market for deposits. This leads to higher revenues. The increase in revenues outweighs the increase in costs so that the profit increases. This shows that interchange agreements facilitate collusion.

We now characterize the equilibria when $a$ is above $a^{*}$. Given the prices of lemma 1 , banks deploy a total number of $\operatorname{ATMs}, n^{* *}(a)$, that leaves consumers with a null surplus: $v\left(n^{* *}(a)\right)+v_{b}=c_{b}+a$. In appendix 3 we show that $n^{* *}(a)$ is the unique equilibrium outcome provided that $a$ is above $a^{*}$ and below some level $a^{* *}$ defined properly in the appendix (expressions (15), (16) and (17)). As $n^{* *}(a)$ is convexly increasing with the interchange fee, requiring $a \leq a^{* *}$ is a condition that notably ensures that equilibrium profits are nonnegative. For a given interchange fee in $\left[a^{*}, a^{* *}\right]$, there are several equilibria where the total deployment is $n^{* *}(a)$ and joint profits are the same, but where banks deploy different number of ATMs. For simplicity, in the following proposition, we characterize the properties of the equilibrium where banks deploy the same number of ATMs.

Proposition 2 Suppose that the banks cooperatively choose $a \in\left[a^{*}, a^{* *}\right]$. There exists an equilibrium $\left\{n_{1}^{* *}(a), \ldots n_{b}^{* *}(a), p_{1}^{* *}(a), \ldots p_{b}^{* *}(a)\right\}$ with $b$ active banks characterized by

$$
v\left(n^{* *}(a)\right)+v_{b}=c_{b}+a
$$

and for any $i \in\{1, \ldots b\}$,

$$
\left\{\begin{array}{l}
n_{i}^{* *}(a)=\frac{n^{* *}(a)}{b} \\
p_{i}^{* *}(a)=c_{b}+a .
\end{array}\right.
$$

\section{Proof. Appendix 3}

This family of equilibria is illustrated in figure 1 (the shape line between $a^{*}$ and $a^{* *}$ ). At $a^{*}$, the two families of equilibria defined in propositions 1 and 2 coincide. We have notably $n^{*}\left(a^{*}\right)=n^{* *}\left(a^{*}\right)$. Note that by expression (4), the profit of bank $i$ is equal to $a / b-c n_{i}^{* *}(a)$. 


\section{Collective setting of the interchange fee}

Banks choose the interchange fee cooperatively anticipating the number of ATMs and the retail prices that result from this choice. The interchange fee is chosen to maximize banks' joint profits $\pi(a)$ :

$$
\pi(a)= \begin{cases}a / b & \text { for } a \in\left[0, a^{*}\right] \\ a-c n^{* *}(a)=v\left(n^{* *}(a)\right)+v_{b}-c_{b}-c n^{* *}(a) & \text { for } a \in\left[a^{*}, a^{* *}\right]\end{cases}
$$

By continuity of the equilibria at $a^{*}$, joints profits are continuous but not differentiable at $a=a^{*}$. To simplify the maximization problem, we make the following assumption on parameters: for the relevant range of $n,{ }^{4}$

$$
v_{b}-c_{b} \geq \frac{v(n)}{b-1}
$$

This assumption is verified when the surplus from basic banking services $v_{b}$ is large enough or when banks are sufficiently numerous. Note it is not very restrictive even with $b=2$ : in this case condition (10) simply states that deposit management activities are more valued than ATM services by banks' customers. Nevertheless, later we will study a case where assumption (10) is not satisfied.

\section{[Insert figure 2 here]}

As joint profits are increasing in the interchange fee up to $a^{*}$, banks never choose an interchange fee lower than $a^{*} . a^{*}$ is the smallest interchange fee inducing an equilibrium where consumers' surplus is nil. Banks choose the interchange fee $a^{*}$ if $\pi(a)$ decreases on $\left[a^{*}, a^{* *}\right]$. It is the case shown in figure $2(\mathrm{a})$. As $\pi(a)$ is concave in $a$, a necessary and

\footnotetext{
${ }^{4}$ In our model $n$ is the number of ATMs per cardholder. A reasonable range of $n$ could be $[0,0.005]$ where 0.005 corresponds to 5000 ATMs per million cardholders. In 2003, there were around 800 ATMs per million inhabitants in European countries as France, Germany, Italy or the UK and around 1400 in the USA or in Canada (figures from the annual report on payment systems, 2004, Norwegian central bank).
} 
sufficient condition for $\pi(a)$ to decrease on $\left[a^{*}, a^{* *}\right]$ is that $\left(v^{\prime}\left(n^{* *}\left(a^{*}\right)\right)-c\right) d n^{* *}\left(a^{*}\right) / d a<0$. Since $d n^{* *}\left(a^{*}\right) / d a>0$ the previous inequality is equivalent to

$$
n^{* *}\left(a^{*}\right)=n^{*}\left(a^{*}\right)>\left(v^{\prime}\right)^{-1}(c) .
$$

In appendix 4 we prove that assumption (10) guarantees inequality (11). Furthermore, according to expression (2) the socially optimal network size, $n^{0}$, is equal to $\left(v^{\prime}\right)^{-1}(c)$. Putting the elements together, we have,

Proposition 3 Under assumption (10), banks choose the interchange fee $a^{*}$ at the cooperative stage and set the ATM deployments and the prices according to proposition 1 for $a=a^{*}$. The resulting equilibrium number of ATMs exceeds the socially optimal level: $n^{*}\left(a^{*}\right)>n^{o}$.

A large number of banks results in a fierce competition to process withdrawals and hence in a large network size for any given level of $a$ (expression (5)). Consumers' gross surplus $v_{b}+v(n)$ is large and banks choose a high interchange fee to extract consumers' surplus through high account fees. The high interchange fee reinforces the initial effect of the large number of banks on the network size: $n^{*}\left(a^{*}\right)$ is over-optimal. Similarly, a large $v_{b}-c_{b}$ means that a significant consumers' surplus can be extracted through a high interchange fee, a large network and high account fees. Interestingly, the interchange fee collectively chosen by banks, $a^{*}$, is increasing in the number of banks $b$, decreasing in the deployment cost $c$, and increasing in $v_{b}-c_{b}$. These predictions are consistent with empirical observations that interchange fees have not decreased despite the fact that deployment costs have fallen or that new banks have entered the ATM market.

Although assumption (10) is not very restrictive for reasonable values of the parameters, it is interesting to study a case where it is not satisfied. Let us for example take $v_{b}-c_{b}=0$ and $v(n)=n^{\varepsilon}$ with $\varepsilon \in(0,1)$ : customers' surplus elasticity is constant and equal to $\varepsilon$. 
Expressions (2), (5) and (6) give

$$
n^{*}\left(a^{*}\right)=\left(\frac{b-1}{b}\right)^{\frac{1}{1-\varepsilon}}\left(\frac{1}{c}\right)^{\frac{1}{1-\varepsilon}} \text { and } n^{o}=\varepsilon^{\frac{1}{1-\varepsilon}}\left(\frac{1}{c}\right)^{\frac{1}{1-\varepsilon}}
$$

If $\varepsilon \geq(b-1) / b$ then we have $n^{*}\left(a^{*}\right) \leq n^{o}$ : a "high" elasticity means that consumer's participation constraint is binding before social optimality is reached. In this case, joint profits are increasing in the right neighborhood of $a^{*}$ as illustrated in figure 2(b). The expressions of joint profits and the total surplus coincide on the range $\left[a^{*}, a^{* *}\right]$ because consumers' surplus is nil for the equilibria of the second family. Consequently, in order to maximize $\pi(a)$, banks are willing to deploy the socially optimal number of ATMs, $n^{0}$. In appendix 5, we show that the interchange fee $a^{o}=\varepsilon^{\varepsilon /(1-\varepsilon)}(1 / c)^{\varepsilon /(1-\varepsilon)}$ belongs to the set $\left[a^{*}, a^{* *}\right]$ and leads to a deployment of $n^{* *}\left(a^{o}\right)=n^{0}$ ATMs. Hence, banks choose $a^{o}>a^{*}$ at the cooperative stage, an equilibrium of the second family is induced, and $n^{\circ}$ ATMs are deployed. The network size is socially optimal. Note that $a^{o}$ is decreasing in $c$ but is now independent from the number of banks. These predictions are also consistent with the empirical evidence about interchange fees.

If $\varepsilon<(b-1) / b$ then we have $n^{*}\left(a^{*}\right)>n^{o}$ : banks choose the interchange fee $a^{*}$ and $n^{*}\left(a^{*}\right)$ ATMs are deployed. We are back to figure 2(a) and the result of proposition 2 holds.

\section{$5 \quad$ Summary and concluding remarks}

We have analyzed how the choice of the interchange fee by banks affects the ATM deployment and the pricing of banking services. Our work shows that the deposit market and the withdrawal market must be studied simultaneously: a high interchange fee strengthens the competition for processing withdrawals but softens the competition for deposits because banks are less willing to accept customers. The latter effect dominates the former. As a result, banks can use the interchange fee as a collusive device. Interestingly the collusive 
effect appears although the accounting outflows and inflows of interchange fees are balanced at equilibrium. The model shows that when there is no surcharges, the interchange fee must exceed the marginal cost of processing a withdrawal to provide banks with incentives to deploy ATMs. Hence the existence of a mark-up of the interchange fee over the marginal processing cost is justified to some extent. However the collusive role of the interchange fee explains that this mark-up is generally excessive: the interchange fee and the size of the shared network exceed their socially optimal levels.

\section{Acknowledgments}

We thank Jorge Padilla, Jean-Charles Rochet, François and Bernard Salanié, Jean Tirole, an editor, and two anonymous referees for helpful suggestions. We are also grateful to the participants of the IDEI conference on payment networks (Toulouse 2002), the LEI-CREST seminar in Paris, and the EARIE (Helsinki 2003). All remaining errors are ours. 


\section{Appendix}

\section{Appendix 1: proof of lemma 1.}

If an equilibrium $\left\{n_{1}^{e}(a), \ldots, n_{b}^{e}(a), p_{1}^{e}(a), \ldots, p_{b}^{e}(a)\right\}$ with $b$ active banks exists, then all banks charge the same price and face a demand $1 / b$. The profit of bank $i$ can be written as

$$
\pi_{i}^{e}=\left(p_{i}^{e}-a-c_{b}\right) \frac{1}{b}+a \frac{n_{i}^{e}}{n^{e}}-c n_{i}^{e}
$$

At equilibrium, no bank $i$ should be willing to deviate in price given the equilibrium deployment profile. There are two cases:

(i) Bank $i$ can deviate to a price lower than $p_{i}^{e}$ to get the entire market. The best deviation is $p_{i}^{e}-\varepsilon$ with $\varepsilon$ positive and very small. The deviation profit is

$$
\pi_{i}^{d}=\left(p_{i}^{e}-\varepsilon-a-c_{b}\right)+a \frac{n_{i}^{e}}{n^{e}}-c n_{i}^{e}
$$

It must be the case that $\pi_{i}^{e} \geq \pi_{i}^{d}$ or $\left(p_{i}^{e}-a-c_{b}\right)(1-1 / b) \leq \varepsilon$. As $\varepsilon$ is positive and arbitrarily small and $1-1 / b>0$, we have necessarily

$$
p_{i}^{e}-a-c_{b} \leq 0
$$

(ii) Bank $i$ can deviate to a price higher than $p_{i}^{e}$ and become inactive. In this case its deviation profit is

$$
\pi_{i}^{d}=a \frac{n_{i}^{e}}{n^{e}}-c n_{i}^{e}
$$

It must be the case that $\pi_{i}^{e} \geq \pi_{i}^{d}$ so that

$$
p_{i}^{e}-a-c_{b} \geq 0
$$

As conditions (12) and (13) must be satisfied at the same time, we have obtained lemma 1. 


\section{Appendix 2: proof of proposition 1.}

We are in the case where $a \leq a^{*}$. In the text, we have proven that given the prices of lemma 1 , each bank $i$ is not willing to deviate in deployment if

$$
n_{i}^{*}=\frac{b-1}{b^{2}} \times \frac{a}{c}
$$

In this case, bank $i$ 's profit is

$$
\pi_{i}^{*}=a \frac{n_{i}^{*}}{n^{*}}-c n_{i}^{*}=\frac{a}{b^{2}} .
$$

Let us check that there is no profitable deviation in both price and deployment. Let $\left(n_{i}^{d}, p_{i}^{d}\right)$ denote a unilateral deviation made by bank $i$. We have to consider four possibilities:

(i) If $p_{i}^{d}<p_{i}^{*}=c_{b}+a$ and $p_{i}^{d} \leq v\left(\sum_{j \neq i} n_{j}^{*}+n_{i}^{d}\right)+v_{b}$, bank $i$ becomes the unique active bank. The deviation profit is

$$
\pi_{i}^{d}=\left[p_{i}^{d}-a-c_{b}\right]+\left[a \frac{n_{i}^{d}}{\sum_{j \neq i} n_{j}^{*}+n_{i}^{d}}-c n_{i}^{d}\right] .
$$

However $p_{i}^{d}-a-c_{b}<0$ and by definition of $n_{i}^{*}$ we have

$$
a \frac{n_{i}^{d}}{\sum_{j \neq i} n_{j}^{*}+n_{i}^{d}}-c n_{i}^{d}<a \frac{n_{i}^{*}}{n^{*}}-c n_{i}^{*} .
$$

As a consequence $\pi_{i}^{d}<\pi_{i}^{*}$.

(ii) If $p_{i}^{d}<p_{i}^{*}$ and $p_{i}^{d}>v\left(\sum_{j \neq i} n_{j}^{*}+n_{i}^{d}\right)+v_{b}$, all banks are inactive: the deviation profit is $-c n_{i}^{d}$ which is clearly smaller than $\pi_{i}^{*}$.

(iii) If $p_{i}^{d}>p_{i}^{*}$ and $p_{i}^{*} \leq v\left(\sum_{j \neq i} n_{j}^{*}+n_{i}^{d}\right)+v_{b}$, bank $i$ becomes inactive and the other banks remain active. Bank $i$ 's deviation profit is

$$
a \frac{n_{i}^{d}}{\sum_{j \neq i} n_{j}^{*}+n_{i}^{d}}-c n_{i}^{d}
$$

which is, by definition of $n_{i}^{*}$, smaller than $\pi_{i}^{*}$.

(iv) If $p_{i}^{d}>p_{i}^{*}$ and $p_{i}^{*}>v\left(\sum_{j \neq i} n_{j}^{*}+n_{i}^{d}\right)+v_{b}$, all banks are inactive: the deviation profit is $-c n_{i}^{d}$ which is clearly smaller than $\pi_{i}^{*}$. 


\section{Appendix 3: proof of proposition 2.}

We are in the case where $a \geq a^{*}$ or

$$
c_{b}+a \geq v\left(\frac{b-1}{b} \times \frac{a}{c}\right)+v_{b} .
$$

Let us define the unique threshold

$$
a^{* *}=\min (\widehat{a}, \widetilde{a})
$$

where $\widehat{a}$ is defined by

$$
v^{\prime}\left(v^{-1}\left(c_{b}+\widehat{a}-v_{b}\right)\right)+\frac{b-1}{b} \times \frac{\widehat{a}}{v^{-1}\left(c_{b}+\widehat{a}-v_{b}\right)}-c=0
$$

and $\widetilde{a}$ is defined by

$$
c v^{-1}\left(c_{b}+\widetilde{a}-v_{b}\right)=\widetilde{a} .
$$

One can verify that $a^{*} \leq a^{* *}$. To characterize the equilibria of the second family, we proceed in two steps. First, we prove that if an equilibrium above $a^{*}$ exists then it must be the case that the total ATM deployment $n^{* *}$ satisfies $c_{b}+a=v\left(n^{* *}\right)+v_{b}$. Second we show that when $a \in\left[a^{*}, a^{* *}\right]$, no bank $i$ is willing to deviate from $n_{i}^{* *}=n^{* *} / b$ and $p_{i}^{* *}=c_{b}+a$.

If an equilibrium with $b$ active banks exists, lemma 1 says we must have $p_{1}^{* *}=\ldots=p_{b}^{* *}=$ $c_{b}+a$. Furthermore it is necessary that consumer's participation constraint is satisfied: $c_{b}+a \leq v\left(n^{* *}\right)+v_{b}$. Let us consider the case where

$$
c_{b}+a<v\left(n^{* *}\right)+v_{b}
$$

In order to prevent deviations in deployment, we must have for any bank $i$,

$$
a \frac{n^{* *}-n_{i}^{* *}}{n^{* * 2}}-c=0
$$

Indeed should condition (19) not hold, bank $i$ could deviate (locally) in deployment while keeping the same price, remain an active bank and increase its profit: a contradiction. Hence, 
suppose (19) holds for any $i$. In this case summing the $b$ FOCs gives $n^{* *}=((b-1) / b)(a / c)$. But in this case there is a contradiction between (14) and (18): we have necessarily

$$
c_{b}+a=v\left(n^{* *}(a)\right)+v_{b}
$$

Given the prices of lemma 1 , the profit of bank $i$ is

$$
\pi_{i}^{* *}=\frac{a}{b}-c n_{i}^{* *}
$$

For an equilibrium to exist, it must be the case that bank $i$ has no incentive to deviate unilaterally from the equilibrium strategies. Let $\left(n_{i}^{d}, p_{i}^{d}\right)$ denote such a deviation. We have several possibilities to consider:

(i) $n_{i}^{d}=0$ and $p_{i}^{d}>c_{b}+a$. Bank $i$ becomes inactive and its deviation profit is 0 . For this deviation not to be profitable, it must be the case that $\pi_{i}^{* *} \geq 0$. This last inequality can be written $c n^{* *}(a) \leq a$ or, equivalently using expression $(20), c v^{-1}\left(c_{b}+a-v_{b}\right) \leq a$. However this last inequality is satisfied because it is simply $a \leq \tilde{a}$ where $\tilde{a}$ defined by (17).

(ii) $0<n_{i}^{d}<n_{i}^{* *}$. Here any bank $j \neq i$ loses its depositors because $p_{j}^{* *}=c_{b}+a>v\left(\sum_{j \neq i} n_{j}^{* *}+\right.$ $\left.n_{i}^{d}\right)+v_{b}$. In this case the best deviation in price for bank $i$ is $p_{i}^{d}=v\left(\sum_{j \neq i} n_{j}^{* *}+n_{i}^{d}\right)+v_{b}: p_{i}^{d}$ is the highest price that permits bank $i$ to be the only active bank. Bank $i$ 's deviation profit is

$$
\pi_{i}^{d}=\left[v\left(\sum_{j \neq i} n_{j}^{* *}+n_{i}^{d}\right)+v_{b}-a-c_{b}\right]+\left[a \frac{n_{i}^{d}}{\sum_{j \neq i} n_{j}^{* *}+n_{i}^{d}}-c n_{i}^{d}\right] .
$$

For the deviation $\left(n_{i}^{d}, p_{i}^{d}\right)$ not to be profitable, it must be the case that $\pi_{i}^{d} \leq \pi_{i}^{* *}(a)$ for any $n_{i}^{d} \in\left(0, n_{i}^{* *}\right)$. As expression (21) is strictly concave in $n_{i}^{d}$, a necessary and sufficient condition is

$$
v^{\prime}\left(n^{* *}\right)+a \frac{n^{* *}-n_{i}^{* *}}{n^{* * 2}}-c \geq 0 \text { for any } i \in\{1, \ldots b\}
$$

Using expression (20) and the fact that $n_{i}^{* *}=n^{* *} / b$ for any $i$, inequality (22) is equivalent to

$$
v^{\prime}\left(v^{-1}\left(c_{b}+a-v_{b}\right)\right)+\frac{b-1}{b} \times \frac{a}{v^{-1}\left(c_{b}+a-v_{b}\right)}-c \geq 0 .
$$


However inequality (23) is satisfied because it is simply $a \leq \hat{a}$ where $\hat{a}$ is defined by (16): the deviation is not profitable.

(iii) $n_{i}^{d} \geq n_{i}^{* *}$ and $p_{i}^{d}>p_{i}^{* *}$. By deviating, bank $i$ becomes inactive and its deviation profit is

$$
\pi_{i}^{d}=a \frac{n_{i}^{d}}{\sum_{j \neq i} n_{j}^{* *}+n_{i}^{d}}-c n_{i}^{d} .
$$

As expression (24) is strictly concave in $n_{i}^{d}$, a necessary and sufficient condition for the deviation not to be profitable is

$$
a \frac{n^{* *}(a)-n_{i}^{* *}(a)}{n^{* * 2}(a)}-c \leq 0 \text { for any } i \in\{1, \ldots b\}
$$

Using expression (20) and the fact that $n_{i}^{* *}=n^{* *} / b$ for any $i$, inequality (25) is equivalent to

$$
\frac{b-1}{b} \times \frac{a}{v^{-1}\left(c_{b}+a-v_{b}\right)}-c \leq 0 .
$$

This last inequality is simply inequality (14) and is satisfied because $a \geq a^{*}$.

(iv) $n_{i}^{d} \geq n_{i}^{* *}$ and $p_{i}^{d}<p_{i}^{* *}$, bank $i$ becomes the only active bank. Its deviation profit is

$$
\left[p_{i}^{d}-a-c_{b}\right]+\left[a \frac{n_{i}^{d}}{\sum_{j \neq i} n_{j}^{* *}+n_{i}^{d}}-c n_{i}^{d}\right] .
$$

However we have $p_{i}^{d}-a-c_{b}<0$ and

$$
a \frac{n_{i}^{d}}{\sum_{j \neq i} n_{j}^{* *}+n_{i}^{d}}-c n_{i}^{d}<a \frac{n_{i}^{* *}}{n^{* *}}-c n_{i}^{* *}
$$

because condition (25) holds. The deviation is not profitable.

Appendix 4: proof that assumption (10) implies that $n^{*}\left(a^{*}\right)>n^{o}=\left(v^{\prime}\right)^{-1}(c)$.

Using expressions (5) and (6), we can define $n^{*}\left(a^{*}\right)$ implicitly by

$$
\frac{b-1}{b} \times \frac{v\left(n^{*}\left(a^{*}\right)\right)+v_{b}-c_{b}}{n^{*}\left(a^{*}\right)}=c .
$$


As $v($.$) is strictly concave and v(0)=0$, we have $v(n) / n>v^{\prime}(n)$ for any $n>0$. Combining this last inequality with assumption (10) and expression (27), we can write

$$
\frac{b-1}{b} \times \frac{v\left(n^{*}\left(a^{*}\right)\right)+v_{b}-c_{b}}{n^{*}\left(a^{*}\right)}=c>\frac{v\left(n^{*}\left(a^{*}\right)\right)}{n^{*}\left(a^{*}\right)}>v^{\prime}\left(n^{*}\left(a^{*}\right)\right)
$$

As $v^{\prime}($.$) is decreasing, we have n^{*}\left(a^{*}\right)>\left(v^{\prime}\right)^{-1}(c)=n^{o}$.

Appendix 5: existence of $a^{o} \in\left[a^{*}, a^{* *}\right]$ with $n^{* *}\left(a^{o}\right)=n^{o}$.

We are in the case $v_{b}-c_{b}=0$ and $v(n)=n^{\varepsilon}$ with $\varepsilon \geq(b-1) / b$. Using expression (2), we have

$$
n^{o}=\varepsilon^{\frac{1}{1-\varepsilon}}\left(\frac{1}{c}\right)^{\frac{1}{1-\varepsilon}}
$$

Note first that

$$
v\left(n^{o}\right)=\varepsilon^{\frac{\varepsilon}{1-\varepsilon}}\left(\frac{1}{c}\right)^{\frac{\varepsilon}{1-\varepsilon}}=a^{o}
$$

so that expression (8) is satisfied for $n^{* *}\left(a^{o}\right)=n^{o}$. Furthermore,

$$
a^{*}=\left(\frac{b-1}{b}\right)^{\frac{\varepsilon}{1-\varepsilon}}\left(\frac{1}{c}\right)^{\frac{\varepsilon}{1-\varepsilon}}, \widetilde{a}=\left(\frac{1}{c}\right)^{\frac{\varepsilon}{1-\varepsilon}} \text { and } \widehat{a}=\left(\frac{b-1}{b}+\varepsilon\right)^{\frac{\varepsilon}{1-\varepsilon}}\left(\frac{1}{c}\right)^{\frac{\varepsilon}{1-\varepsilon}}
$$

so that $a^{o} \geq a^{*}, a^{o} \leq \widetilde{a}$ and $a^{o} \leq \widehat{a}$. As $a^{* *}=\min (\widetilde{a}, \widehat{a})$, we have $a^{o} \in\left[a^{*}, a^{* *}\right]$. 


\section{References}

[1] Ardizzi, G. and Coppola G., 2002. The Italian case study: interchange fee, market structure and cost efficiency in the retail payment system. Mimeo

[2] Balto, D.A., 2000, The problem of interchange fees: costs without benefits ?, European Competition Law Review, 21, pp 215-224.

[3] Bolt, W., 2003, Retail Payments in the Netherlands: some facts and some theory, Working Paper, De Nederlandsche Bank.

[4] Croft, E. and Spencer B., 2004. Fees and Surcharging in Automatic-Teller Machine Networks: Non-Bank ATM Providers versus Large Banks. NBER working paper w9883.

[5] Cruickshank, D., 2000. Competition in UK Banking: A report to the Chancellor of the Exchequer. Banking review.

[6] Ganguly B. and Milne A., 2001. Retail Payments in the UK: is there a problem of lack of competition ?. Working Paper, City University Business School.

[7] GIE CB (Groupement d'intérêt économique cartes bancaires), 2004. Internet address: www.cartes-bancaires.com

[8] LINK Network, 2004. Internet address: www.link.co.uk

[9] Massoud, N. and Bernhardt, D., 2002a. Rip-off ATM surcharges, RAND Journal of Economics, Vol. 33, pp 96-115.

[10] Massoud, N. and Bernhardt, D., 2002b. Endogenous ATM Concentration. Mimeo, School of Business, University of Alberta, Canada. 
[11] Massoud, N., Sanders A. and Scholnick B., 2004. The Impact of ATM Surcharges on Large versus Small Banks: is there a switching effect? The Journal of Business (forthcoming).

[12] Matutes, C. and Padilla, A.J., 1994. Shared ATM networks and banking competition. European Economic Review, Vol 38, pp 1113-1138.

[13] McAndrews, J.J., 1998. ATM Surcharges, Current Issues in Economics and Finance. Federal Reserve bank of New York. Volume 4, Number 4.

[14] McAndrews, J.J., 2003. Automated Teller Machine Network Pricing - A Review of the Literature. The Review of Network Economics. Vol 2, Issue 2, pp 146-158.

[15] Reserve Bank of Australia and Australian Competition and Consumer Commission. 2000. Debit and Credit Card Schemes in Australia: a Study of Interchange Fees and Access. 


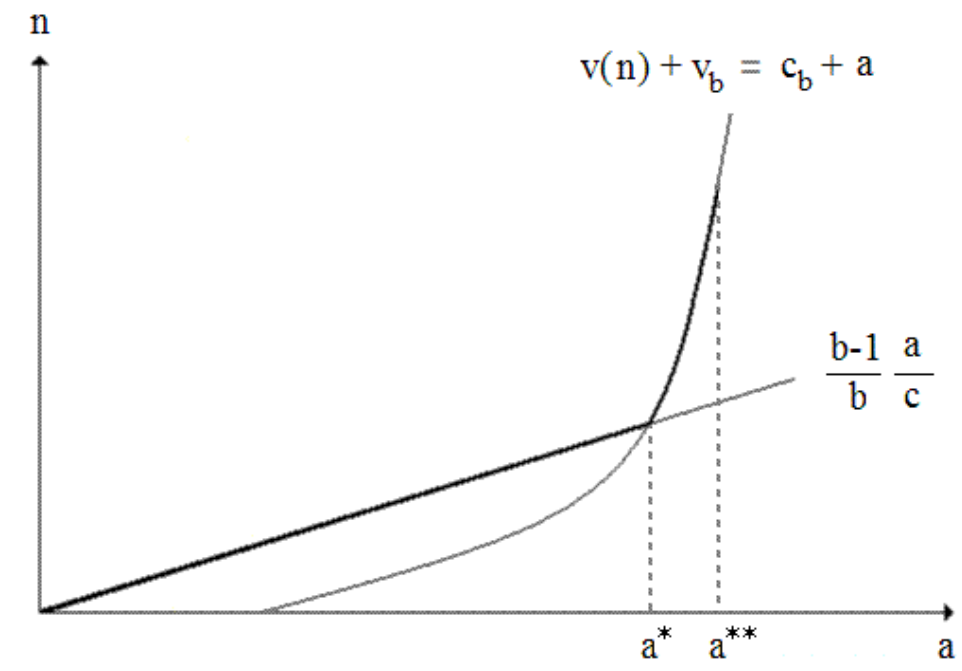

Figure 1: Equilibrium ATM deployment as a function of the interchange fee.

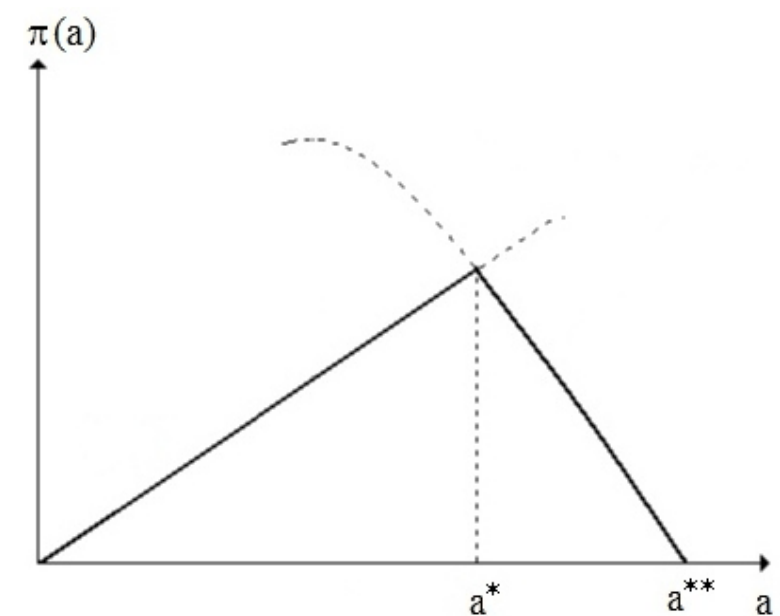

(a)

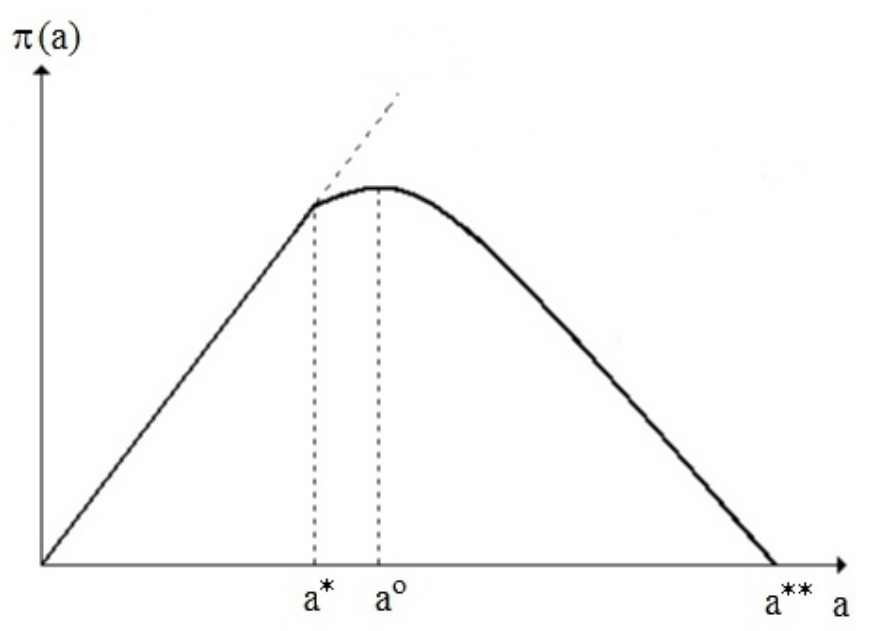

(b)

Figure 2: Banks' joint profits when (a) $n^{*}\left(a^{*}\right)>n^{o}$ and (b) $n^{*}\left(a^{*}\right) \leq n^{o}$. 